the 1990 s, specialist outreach clinics were established in which specialists travelled to general practitioner clinics to see patients. Again these were associated with high patient satisfaction and reduced waiting times but increased costs to the NHS.

So from an NHS perspective, general practitioner with special interest clinics look as if they are effective mainly in providing better access but will do this in a cost effective manner only if the increased capacity cannot be provided in hospital clinics. In terms of safety and clinical effectiveness, general practitioner with special interest services need to be set up in close collaboration with local specialists, who should provide ongoing training and education. This has not always been the case, and many general practitioners with special interests are not currently receiving nationally agreed levels of training. ${ }^{4}$

The effect of increasing specialist capacity on general practitioners' rates of referral is another key factor that will affect the cost effectiveness of general practitioner with special interests. Several studies indicate that general practitioners with special interests are associated with an increase in number of patients referred $^{5-7}$ Maddison et al found a doubling in the number of patients referred to a redesigned musculoskeletal service, with no change in the proportion of patients listed for surgery, implying that the increase in referrals addressed previously unmet needs. ${ }^{7}$ Sanderson, however, found that some of the observed increase in referrals was of patients who would not previously have been referred. ${ }^{5}$

The development of general practitioner with special interest services is an effective method of increasing access to specialist services when capacity cannot be increased within hospital clinics. They are unlikely, however, to be a cheap option. General practitioner with special interest clinics may cost more than the equivalent hospital based clinics and they may generate increased demand. In the context of the forthcoming white paper on care outside hospitals, general practitioners with special interests should be regarded as a positive development in improving access and patient satisfaction. Healthcare planners, however, need to understand that general practitioners with special interests will increase overall NHS costs and are probably not the most efficient way of increasing specialist capacity.

Competing interests: None declared.

Salisbury C, Noble A, Horrocks S, Crosby Z, Harrison V, Coast J, et al Evaluation of a general practitioner with a special interest service for dermatology: randomised controlled trial. BMJ 2005;331:1441-4.

2 Coast J, Noble S, Noble A, Horrocks S, Asim O, Peters TJ, et al. Economic evaluation of a general practitioner with special interest led dermatology service in primary care. BMJ 2005;331:1444-8.

3 Roland M, Shapiro J, eds. Specialist outreach clinics in general practice. Oxford: Radcliffe Medical Press, 1998.

4 Schofield JK, Irvine A, Jackson S, Adlard T, Gunn S, Evans N. General practitioners with a special interest in dermatology: results of an audit against Department of Health (DH) guidance. Brit J Dermatol 2005; 153(suppl 1):O-1.

5 Sanderson D. Evaluation of the GPs with special interests (GPwSIs) pilot projects within the action on ENT programme. York: York Health Economics Consortium, 2002.

6 Duckett S, Casserly H. Orthopaedic GP fellowship: does it work? Ann R Coll Surg Engl 2003;85:195-6.

7 Maddison P, Jones J, Breslin A, Barton C, Fleur J, Lewis R, et al. Improved access and targeting of musculoskeletal services in northwest Wales: targeted early access to musculoskeletal services (TEAMS) programme. BMJ geted early access
2004;329:1325-7.

doi $10.1136 / \mathrm{bmj} .38676 .769711 .7 \mathrm{C}$

\title{
Deprivation and volunteering by general practices: cross sectional analysis of a national primary care system
}

\author{
Daniel Mackay, Matt Sutton, Graham Watt
}

Since the inception of the NHS, primary medical services in the United Kingdom have been mainly delivered by a large number of general practices operating as independent businesses. As well as providing general medical services, practices can participate in several voluntary activities associated with quality care and service development.

\section{Methods and results}

Our study population comprised 5.35 million people served by 1050 general practices and is a complete national sample of patients and practices.

We ranked general practice populations using a modified version of the Scottish Indices of Deprivation 2003, ${ }^{1}$ including currently available data for education, income, and employment, but excluding data for access and health. We used practice mean values to divide the population into 10 groups of equal size, from tenth 1 (least deprived) to tenth 10 (most deprived). We analysed the deprivation related distribution of population health indicators, practice characteristics, and participation in voluntary development schemes, using data for 2001-2 (table).

By design, the composite deprivation index increases across tenths with the largest increase between tenths 9 and 10. All three measures of ill health show a significant positive trend and greater than 2.5-fold variation across tenths.

On average, populations of 530000 people were served by 353 whole time equivalent general practitioner principals, with little variation between tenths. The total whole time equivalent of general practitioners, however, including non-principals and doctors in training, was $11 \%$ higher (437.1 $v 392.0$, $\mathrm{P}<0.001$ ) in tenths 1-5 (least deprived) compared with tenths 6-10 (most deprived).

On average, each tenth was served by 105 general practices, with larger numbers of practices in the most rural (tenth 2) and deprived (tenth 10) areas. This
General Practice and Primary Care, Division of

Community Based Sciences, University of Glasgow,

Glasgow G12 9LX

Daniel Mackay research fellow Graham Watt professor of general practice

Health Economics Research Unit, University of Aberdeen, Aberdeen AB25 2ZD

Matt Sutton professor of health economics

Correspondence to: G Watt

gcmw1j@ clinmed.gla.ac.uk

BMJ 2005;331:1449-51 
Characteristics of populations, medical manpower and general practices in tenths of the general population stratified by socioeconomic deprivation

\begin{tabular}{|c|c|c|c|c|c|c|c|c|c|c|c|c|c|c|c|c|}
\hline \multirow[b]{2}{*}{$\begin{array}{l}\text { Deprivation } \\
\text { status }\end{array}$} & \multicolumn{5}{|c|}{ Demography } & \multicolumn{4}{|c|}{ Population characteristics } & \multicolumn{3}{|c|}{ Practice characteristics } & \multicolumn{4}{|c|}{ Practice activities } \\
\hline & $\begin{array}{c}\text { Registered } \\
\text { patients }\end{array}$ & Practices & $\begin{array}{l}\text { WTE } \\
\text { principals }\end{array}$ & $\begin{array}{c}\text { Non- } \\
\text { principals }\end{array}$ & $\begin{array}{l}\text { Total } \\
\text { GPs }\end{array}$ & $\begin{array}{l}\text { Composite } \\
\text { deprivation }\end{array}$ & SMR $<75$ & SIR & SHR & $\begin{array}{l}\text { Single } \\
\text { handed }\end{array}$ & $\begin{array}{c}\text { Young } \\
\text { GPS }\end{array}$ & $\begin{array}{c}\text { Large } \\
\text { list }\end{array}$ & PA & SPICE & Training & PMS \\
\hline \multicolumn{17}{|l|}{ Tenth: } \\
\hline $\begin{array}{l}1 \text { (least } \\
\text { deprived) }\end{array}$ & 535290 & 94 & 344.2 & 87 & 431.2 & -1.18 & 62.1 & 65.8 & 54.7 & 0.04 & 0.06 & 0.15 & 0.33 & 0.23 & 0.51 & 0.12 \\
\hline 2 & 537391 & 112 & 378.3 & 88 & 466.3 & -0.76 & 76.4 & 77.2 & 67.6 & 0.05 & 0.07 & 0.15 & 0.30 & 0.22 & 0.43 & 0.16 \\
\hline 3 & 534250 & 114 & 362.7 & 73 & 435.7 & -0.52 & 85.7 & 83.9 & 77.1 & 0.04 & 0.04 & 0.15 & 0.24 & 0.13 & 0.40 & 0.05 \\
\hline 4 & 539389 & 95 & 363.9 & 73 & 436.9 & -0.35 & 91.9 & 88.5 & 83.5 & 0.02 & 0.07 & 0.09 & 0.28 & 0.22 & 0.45 & 0.07 \\
\hline 5 & 529883 & 97 & 354.2 & 61 & 415.2 & -0.17 & 96.5 & 95.9 & 94.1 & 0.04 & 0.06 & 0.16 & 0.26 & 0.21 & 0.29 & 0.12 \\
\hline 6 & 535521 & 108 & 354.9 & 58 & 412.9 & 0.07 & 99.00 & 101.2 & 101.6 & 0.05 & 0.04 & 0.09 & 0.30 & 0.17 & 0.34 & 0.08 \\
\hline 7 & 536082 & 93 & 352.0 & 46 & 398.0 & 0.28 & 105.5 & 106.5 & 108.9 & 0.03 & 0.10 & 0.09 & 0.30 & 0.13 & 0.28 & 0.09 \\
\hline 8 & 535599 & 105 & 338.7 & 34 & 372.7 & 0.51 & 115.2 & 114.4 & 120.4 & 0.06 & 0.06 & 0.20 & 0.21 & 0.03 & 0.21 & 0.06 \\
\hline 9 & 538462 & 105 & 332.0 & 39 & 371.0 & 0.78 & 119.9 & 121.7 & 132.3 & 0.07 & 0.11 & 0.22 & 0.15 & 0.15 & 0.20 & 0.05 \\
\hline $\begin{array}{l}10 \\
\text { (most } \\
\text { deprived) }\end{array}$ & 528283 & 124 & 352.2 & 53 & 405.2 & 1.47 & 150.1 & 143.2 & 170.0 & 0.07 & 0.15 & 0.11 & 0.12 & 0.13 & 0.22 & 0.04 \\
\hline Sum & 5350150 & 1047 & 3533.10 & 612 & 4145.1 & - & - & - & - & - & - & - & - & - & - & - \\
\hline Mean & 535015 & - & 353.31 & - & - & - & 100.2 & 99.8 & 100.9 & 0.05 & 0.08 & 0.14 & 0.25 & 0.16 & 0.33 & 0.08 \\
\hline SIIई & - & - & - & - & - & - & 78.0 & 73.9 & 108.6 & 0.04 & 0.08 & 0.02 & -0.18 & -0.13 & -0.34 & -0.09 \\
\hline RIII & - & - & - & - & - & - & 0.78 & 0.74 & 1.08 & 0.84 & 0.99 & 0.12 & -0.74 & -0.81 & -1.01 & -1.05 \\
\hline $\mathrm{P}$ value ${ }^{\star \star}$ & - & - & - & - & - & - & $<0.001$ & $<0.001$ & $<0.001$ & 0.21 & 0.03 & 0.51 & $<0.001$ & $<0.001$ & $<0.001$ & 0.01 \\
\hline
\end{tabular}

WTE=Whole time equivalent; SMR $>75=$ All cause deaths under 75; SIR=Standardised limiting long term illness; SHR=Standardised "not good" self assessed health;

$\mathrm{PA}=$ Practice accreditation; SPICE=Scottish Programme for Improving Clinical Effectiveness participant practice; PMS=Personal medical services practice.

${ }^{*}$ Mean age $<38$ years.

†More than 1900 patients per WTE.

†Royal College of General Practitioners accredited training practice.

$\S S I I$ is the slope measure of inequality and is obtained by regressing the values of the variable of interest for each tenth on the cumulative proportions of the

population. The SII therefore represents the expected difference between the top and bottom tenth as measured by the average slope of the variable across all of the

tenths. It is positive (negative) when the variable takes higher (lower) values in more deprived (affluent) tenths.

IRII is the SII divided by the mean and can therefore be compared across variables.

${ }^{* *}$ The significance of the trend is measured using the $t$ ratio for the slope coefficient.

reflects the higher proportion of single handed and small practices in such areas. General practitioners' partnerships in deprived areas also have lower average ages and a higher proportion without a female general practitioner.

Variation between affluent and deprived areas is more than twofold (tenths $1-3 v 7-10, \mathrm{P}<0.001$ ) in the proportion of practices involved in training general practitioners. Although younger general practitioners are more likely to work in deprived areas, it is less likely that they could have been trained there.

Potential markers of quality general practice, such as practice accreditation (see www.rcgp-scotland.org.uk/ products/practice.asp), and enhanced data collection schemes, such as the Scottish Programme for Improving Clinical Effectiveness (SPICE, see www.ceppc.org/ spice/index.shtml), were $80 \%(\mathrm{P}<0.001)$ and $90 \%$ $(\mathrm{P}<0.001)$ more common, respectively, in the more affluent practices (tenths 1-3) than in the more deprived practices (tenths 7-10).

\section{What is already known on this topic}

The aim of the NHS is to provide comprehensive health care according to need

\section{What this study adds}

The provision and development of primary medical services varies inversely with need, particularly if promoted on a voluntary basis; the NHS needs to do more in promoting primary care for the population as a whole
Although the Personal Medical Services initiative was launched with the intention of improving clinical care in rural and deprived areas, ${ }^{2}$ participation was 2.2 times more common in affluent areas $(\mathrm{P}<0.001)$.

\section{Comment}

Insofar as the leading edge of general practice may be characterised by participation in quality schemes, health service initiatives, and postgraduate training, these activities feature about twice as often in practices serving more affluent areas. Although there are training and pioneering practices in poor areas, they are exceptions to the general rule.

These activities are not centrally distributed but are taken up by practices that volunteer. Practices serving the most deprived areas are less likely to volunteer, possibly because they are so consumed by dealing with increased levels of morbidity, without increased levels of medical manpower, that they are unable or unwilling to take on additional activities. ${ }^{3}$

The patterns described in this paper are generally hidden from public view, as a result of the convention of reviewing healthcare services at the level of large administrative areas, with substantial social heterogeneity. A different focus is required to monitor the leading edges of primary care development.

Arguably, the greatest challenge facing any national health service aiming for the equitable delivery of high quality care is to develop the best examples of care and the most attractive professional career opportunities in populations where need is greatest. ${ }^{4}$ The NHS has much more to do in tackling this challenge. 
We thank, for providing or facilitating access to the data, Rosalia Munoz-Arroyo, Jennifer Bishop, Chris Povey, Matthew Armstrong, Craig Dougan, Mag Conway, James McNally, and Bill Gold at ISDScotland; Malcolm Campbell and Cath Macdonald at the Royal College of General Practitioners, Scotland; and Alasdair Coutts at the Primary Care Clinical Informatics Unit, University of Aberdeen.

Contributors: DM, MS, and GW jointly contributed to the design and interpretation of the study and the writing of the paper. DM and MS collated the data, and DM undertook the analysis. GW wrote the final version of the paper with contributions from DM and MS. GW is guarantor.

Funding: DM and MS were funded by the Platform Project when the majority of this work was undertaken. The Platform Project is a collaborative venture between the Universities of Aberdeen,
Dundee, Edinburgh, and Glasgow, with ISDScotland and the Royal College of General Practitioners. It was jointly funded by the Chief Scientist Office (RDG HR01012) and the Scottish Higher Education Funding Council (OOB/3/67).

Competing interests: None declared.

Ethical approval: Not needed.

1 Noble M, Smith G, Wright G, Dibben C, Lloyd M, Ratcliffe A, McLellan D, Sigala M, Anttila C. Scottish indices of deprivation 2003. Edinburgh: Scottish Sigala M, Anttila

2 McKeon AJ. Personal medical services pilots under the NHS (Primary Care) Act 1997: a comprehensive guide, 1997. London: Department of Health, 1997.

3 Watt G. The inverse care law today. Lancet 2002;360:252-4.

4 Scottish Executive. Our national health: a plan for action, a plan for change. Edinburgh: Scottish Executive Health Department, 2000.

(Accepted 6 September 2005)

\title{
Overprescribing antidepressants to children: pharmacoepidemiological study in primary care
}

\author{
Kathleen Bennett, Mary Teeling, John Feely
}

Depression is associated with considerable morbidity and risk of suicide. About $20 \%$ of adults and $2 \%$ of those aged 0-18 years are affected at anytime. ${ }^{1}$ Although widely used to manage adult depression, no antidepressants are licensed for use in children. Recent attention has focused on the potential risk of suicide in children. We aimed to evaluate the level of use of antidepressants in adults and children in Ireland, the drug type and duration of use, and the changes in prescription rates over time.

\section{Participants, methods, and results}

We used the General Medical Services' claims database. The scheme, which is means tested, provides free health services to about $30 \%$ of the Irish population (representing 1.24 million people) and $28 \%$ of all children. $^{2}$ All prescription items are coded using WHO's anatomical therapeutic chemical classification (ATC) and basic demographic information (age and sex) are recorded. As age is categorised we classified people aged $0-15$ years and $\geq 16$ years as children and adults respectively. We identified people who had been prescribed antidepressants (ATC N06A-X) between January 2001 and August 2004. Prevalence was based on 2003 data. We used Poisson regression to examine trends, expressed as the average monthly relative change in prescription rate (that is, a rate ratio of 0.98 represents as a relative rate change of $-2 \%$ ). We used SAS 9.0 (SAS, Cary, North Carolina) for all analyses.

In 2003, antidepressants were prescribed to 1079 children, representing $0.43 \%$ of the eligible population, and to 153863 adults, representing $16.9 \%$ of the population (ages 16-24, 9\%; 25-74, 17.9\%; $\geq 75$ years, $18.3 \%$ ). Girls (odds ratio $1.60,95 \%$ confidence interval 1.42 to 1.80$)$ and women $(1.40,1.38$ to 1.42$)$ were significantly more likely to receive antidepressants than their male counterparts. Type of antidepressant was similar in adults and children, with selective serotonin reuptake inhibitors the most commonly prescribed group. About 58\% of children received only one prescription for antidepressants, but $19.4 \%$ received three or more months of prescriptions in 2003. In contrast, $23.5 \%$ of adults received just one prescription, and $66.5 \%$ received three or more months' worth, reflecting more chronic use.

The test for interaction of time by population group (adult or child) was significant $(\mathrm{P}<0.001)$, indicating different trends for the two groups, as was the interaction of time by type of antidepressant (selective serotonin reuptake inhibitor versus tricyclics) for children $(\mathrm{P}<0.001)$.

The overall trend in antidepressant prescribing in children showed a significant reduction between January 2001 and August 2004 (figure; rate ratio - 0.45\%, $95 \%$ confidence interval $-0.60 \%$ to $-0.30 \%$, $\mathrm{P}<0.001)$. A similar trend was noted for tricyclic antidepressants $(-1.80 \%,-2.10 \%$ to $-1.50 \%)$. However prescribing patterns for selective serotonin reuptake inhibitors in children did not show an overall downward trend $(0.17 \%,-0.03 \%$ to $0.37 \%, \mathrm{P}=0.091)$.

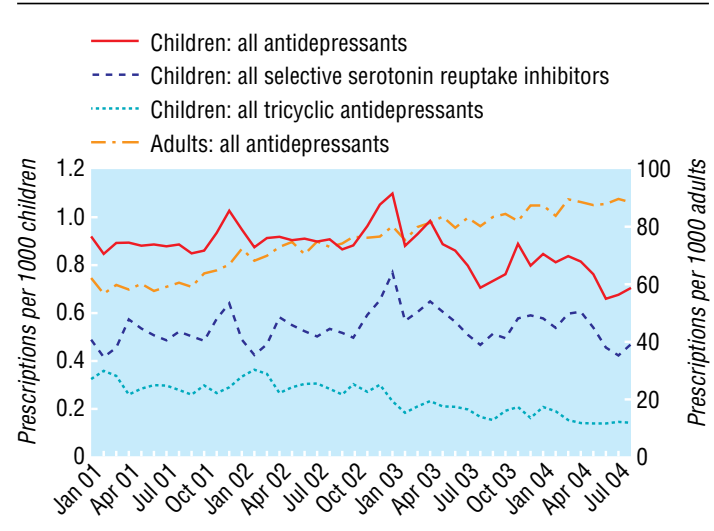

Prescribing rate of antidepressants in Irish children and adults from January 2001 to August 2004

\section{Papers p 1435}

Department of Pharmacology and Therapeutics, Trinity Centre for Health Sciences, St James's Hospital, Dublin 8, Republic of Ireland

Kathleen Bennett statistician Mary Teeling lecturer in clinical pharmacology John Feely professor of pharmacology and therapeutics

Correspondence to: K Bennett bennettk@tcd.ie

BMJ 2005;331:1451-2 